\title{
DUAL BOUNDARY ELEMENT ANALYSIS OF CLOSED CRACKS
}

\author{
JUKKA TUHKURI \\ Helsinki University of Technology, Ship Laboratory, Tietotie 1, FIN-02150 Espoo, Finland
}

\begin{abstract}
A two-dimensional boundary element method for analysis of closed or partially closed cracks under normal and frictional forces is developed. The single domain dual formulation is used. As a contact problem is non-linear due to the friction phenomena at the crack interface and also because of the boundary conditions which may change during the loading, it is formulated in an incremental and iterative fashion. The stress intensity factors are calculated with the $J$-integral method. Also crack growth is considered. Several benchmark cases have been analysed to verify the results given by the method. The stress intensity factors and crack paths calculated are similar to those given in the literature. (C) 1997 by John Wiley \& Sons, Ltd.
\end{abstract}

Int. J. Numer. Meth. Engng., 40, 2995-3014 (1997)

No. of Figures: 7. No. of Tables: 7. No. of References: 40.

KEY WORDS: boundary element method; fracture mechanics; contact mechanics; brittle fracture

\section{INTRODUCTION}

Boundary Element Methods (BEM) are numerical methods in continuum mechanics. ${ }^{1-3}$ The basic task in any boundary element analysis of fracture mechanics is to solve the problem that arises because two nodes on opposite sides of a crack have equal coordinates. One method to avoid this problem is to divide the domain into subdomains, so that the crack surfaces are not in the same domain. ${ }^{4}$ Another method is the single domain dual boundary element method, ${ }^{5}$ where one crack surface is modelled by using the displacement boundary integral equation and the other surface by using the traction boundary integral equation. A central advantage of the dual BEM is its computational efficiency in modelling crack growth where new elements need to be created as the crack propagates. In the subdomain method remeshing is needed, because the domain boundaries are defined by the crack surfaces. For a body with multiple cracks this can be time consuming. However, all remeshing is avoided by using the single domain dual BEM. The dual BEM has been developed for two-dimensional analysis of crack problems by Portela et al., ${ }^{6-9}$ and for three-dimensional problems by Gray et al. ${ }^{10}$ These formulations are well suited for crack propagation analyses, but their applications are limited to cases where the cracks are open.

An analysis of closed cracks involves additional features compared to analyses restricted to open cracks because of the normal and tangential (frictional) forces arising on the crack surfaces

Correspondence to: Jukka Tuhkuri, Helsinki University of Technology, Ship Laboratory, Tietotie 1, FIN-02150 Espoo, Finland

Contract grant sponsor: Academy of Finland

CCC 0029-5981/97/162995-20\$17.50 
in contact. In general, areas of stick, slip, or separation can occur along one crack. A contact between crack surfaces can be analysed as a general contact mechanics problem of two elastic bodies. The central feature in such problems is that the contact area and the contact mode are not known beforehand, but are solved during the analysis. Therefore, the problem must be solved iteratively. In addition, the analysis must be incremental as a contact problem is non-linear due to the friction phenomena and also because of the boundary conditions, which may change when the load changes. In some special cases where all the stress components within the system increase or decrease in a uniform manner, the incremental formulation and a total formulation will give equal results, but, in general, the two approaches cannot be expected to give the same result.

The boundary element method is attractive for contact analyses because the contact variables at an interface (displacements and tractions) are directly the unknowns that are solved. Andersson et al. ${ }^{11,12}$ appear to be the first to apply BEM to contact mechanics. The more recent studies include those by Paris and Garrido, ${ }^{13}$ Man et al. ${ }^{14}$ and Olukoko et al. ${ }^{15}$ Boundary element analyses of closed cracks are not as numerous as studies on general contact problems. Karami and Fenner ${ }^{16}$ and Selvadurai and $\mathrm{Au}^{17,18}$ used the subdomain formulation and Crouch and Starfield ${ }^{3}$ and Scavia ${ }^{19}$ used the displacement discontinuity method in two-dimensional problems involving mixed mode fracture and crack closure.

In this paper a two-dimensional dual boundary element formulation for analysis of closed or partially closed cracks under normal and frictional forces is developed. Also the propagation of cracks is considered. This formulation is an alternative to the subdomain and displacement discontinuity methods and allows a simple analysis without the need for multiple domains with artificial boundaries. As such a contact problem is non-linear, it is formulated in an incremental and iterative fashion. The present formulation is an extension of the method for analysis of open cracks developed by Portela et al. ${ }^{6-9}$

\section{THE DUAL BOUNDARY ELEMENT METHOD}

\subsection{Boundary integral equation formulations}

The present formulation ${ }^{20}$ of a direct boundary element method is based on the works of Rizzo $^{21}$ and Cruse. ${ }^{22}$ The material is assumed to be linearly elastic, isotropic and homogeneous. It is also assumed that body forces are zero and displacements are infinitesimal. The notation used is the Cartesian tensor notation. Repeated suffixes imply summation, and a comma is used to indicate partial differentiation. The displacement boundary integral equation for a domain with a smooth boundary $S$ is ${ }^{22}$

$$
\frac{1}{2} u_{i}(P)=-\int_{S} T_{i j}(P, Q) u_{j}(Q) \mathrm{d} S+\int_{S} U_{i j}(P, Q) t_{j}(Q) \mathrm{d} S
$$

where $P$ is a collocation point, $Q$ a field point, $u_{j}$ a displacement component and $t_{j}$ a traction component. $U_{i j}$ and $T_{i j}$ are the fundamental solutions for displacements and tractions, respectively, which are for plane strain case: ${ }^{1,2}$

$$
\begin{aligned}
& U_{i j}(P, Q)=\frac{1+v}{4 \pi E(1-v)}\left[(3-4 v) \ln \left(\frac{1}{r}\right) \delta_{i j}+r_{, i} r_{, j}\right] \\
& T_{i j}(P, Q)=\frac{-1}{4 \pi(1-v) r}\left\{\frac{\partial r}{\partial n}\left[(1-2 v) \delta_{i j}+2 r_{, i} r_{, j}\right]+(1-2 v)\left(n_{i} r_{, j}-n_{j} r_{, i}\right)\right\}
\end{aligned}
$$


where $r$ is the distance between $P$ and $Q$, and $n_{i}$ is a component of the outward normal of the surface $S$ at the field point $Q$. By differentiating the displacement boundary integral equation, a traction boundary integral equation can be formed $\mathrm{as}^{22}$

$$
\frac{1}{2} t_{i}(P)=-n_{j}(P) \int_{S} S_{k i j}(P, Q) u_{k}(Q) \mathrm{d} S+n_{j}(P) \int_{S} D_{k i j}(P, Q) t_{k}(Q) \mathrm{d} S
$$

where the fundamental solutions $S_{k i j}$ and $D_{k i j}$ are for a plane strain problem: ${ }^{1,2}$

$$
\begin{aligned}
D_{k i j}(P, Q)= & \frac{1}{4 \pi(1-v) r}\left[(1-2 v)\left(r_{, i} \delta_{j k}+r_{, j} \delta_{k i}-r_{, k} \delta_{i j}\right)+2 r_{, i} r_{, j} r_{, k}\right] \\
S_{k i j}(P, Q)= & \frac{E}{4 \pi\left(1-v^{2}\right) r^{2}}\left\{2 r_{, m} n_{m}\left[(1-2 v) \delta_{i j} r_{, k}+v\left(r_{, j} \delta_{i k}+r_{, i} \delta_{j k}\right)-4 r_{, i} r_{, j} r_{, k}\right]\right. \\
& \left.+2 v\left(n_{i} r_{, j} r_{, k}+n_{j} r_{, i} r_{, k}\right)+(1-2 v)\left(2 n_{k} r_{, i} r_{, j}+n_{j} \delta_{i k}+n_{i} \delta_{j k}\right)-(1-4 v) n_{k} \delta_{i j}\right\}
\end{aligned}
$$

Both the displacement and traction boundary integral equations (BIE) can be independently used to formulate a boundary element method. However, a mixed formulation can also be formed. This is what is done in the dual boundary element method where the displacement BIE is applied when the source point is on one of the crack boundaries, and the traction BIE is applied when the source point is on the opposite crack boundary. ${ }^{5-9}$ By using this method, the problem caused by two crack nodes having equal coordinates is avoided, because there are now two equations for the two nodes.

\subsection{Boundary element method formulation}

In order to solve the equations (1) and (4) numerically, the boundary $S$ is divided into boundary elements. Taking each node in turn as the collocation point $P$, and performing the integrations, a system of linear algebraic equations can be formed as ${ }^{1,2}$

$$
[H]\{u\}=[G]\{t\}
$$

where the influence matrices $[H]$ and $[G]$ contain integrals of the kernels $U_{i j}, T_{i j}, D_{k i j}$ and $S_{k i j}$. When performing these integrations, it must be taken into account that the kernels become singular when $r \rightarrow 0$ (see the appendix). The displacement vector $\{u\}$ and the traction vector $\{t\}$ contain both unknown and known values. By rearranging all the known values on the right-hand side and all the unknowns on the left-hand side, equation (7) becomes

$$
[A]\{x\}=\{f\}
$$

which is then solved.

Figure 1 shows the discretization strategy used by Portela et al. ${ }^{6-9}$ and adopted also here. The crack surfaces are modelled by discontinuous straight quadratic boundary elements shown in Figure 2. The remaining boundaries are discretized with continuous quadratic boundary elements. Discontinuous elements are used in order to verify continuity of the tractions at the source point in the traction BIE. Straight crack elements are used for simplicity. As in the present dual BE formulation no special crack tip elements are used, the $1 / \sqrt{r}$-type singularity is not modelled. This is different than in many other BE formulations. ${ }^{4,17,18}$ The justification for ignoring the singularity is the assumed local nature of the singularity, the use of discontinuous elements when 


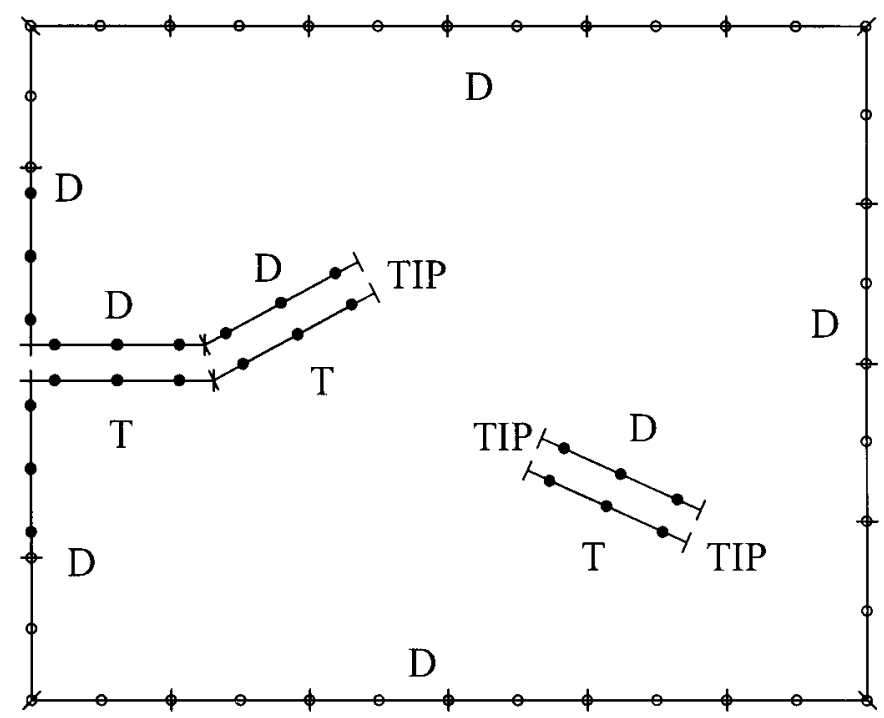

Figure 1. Discretization strategy used in the dual BE method. ${ }^{6-9} D$ and $T$ refer to displacement and traction BIE, respectively. The solid and hollow circles are nodes in discontinuous and continuous quadratic boundary elements, respectively

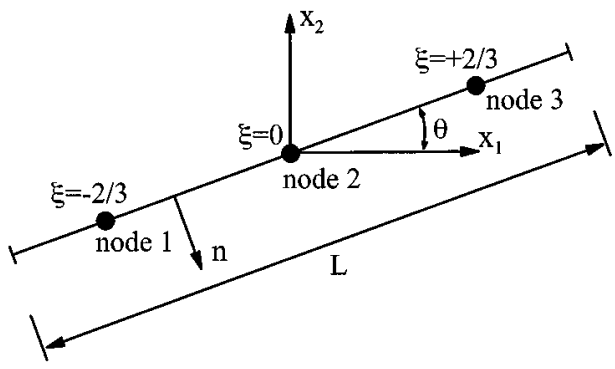

Figure 2. A discontinuous crack element of length $L$. The nodes are positioned at points $\xi=-2 / 3, \xi=0$ and $\xi=$ $+2 / 3 . n$ is the outward normal

no nodes are located at the close vicinity of the crack tip, and the use of the $J$-integral to calculate the stress intensity factors.

\section{DUAL BOUNDARY ELEMENT FORMULATION OF A CONTACT PROBLEM INVOLVING CRACK SURFACES}

\subsection{Introduction}

The dual BEM have been used successfully by Portela et al. ${ }^{6-9}$ to calculate stress intensity factors and to analyse static crack growth. However, their analysis was restricted to cases where the cracks were open, because they assumed that the crack surfaces are traction free. In the 
following, the dual BEM is extended to allow analysis of closed or partially closed cracks with friction. That work is comprised of the following steps:

(i) formulation of an incremental dual boundary element method,

(ii) description of contact conditions,

(iii) description of an interface constitutive law,

(iv) modelling of crack growth,

(v) formulation of a numerical algorithm.

In addition, calculation of the influence matrices $[H]$ and $[G]$, which includes analytical integrations, is explained in the appendix.

\subsection{Incremental dual boundary element equations}

In an incremental formulation a change from the state $C^{m-1}$ to the state $C^{m}$ is analysed. The incremental form of the displacement boundary integral equation is ${ }^{12}$

$$
\frac{1}{2} \Delta u_{i}^{m}(P)=-\int_{S} T_{i j}(P, Q) \Delta u_{j}^{m}(Q) \mathrm{d} S+\int_{S} U_{i j}(P, Q) \Delta t_{j}^{m}(Q) \mathrm{d} S
$$

In an analogous manner, the incremental form of the traction boundary integral equation is

$$
\frac{1}{2} \Delta t_{i}^{m}(P)=-n_{j}(P) \int_{S} S_{k i j}(P, Q) \Delta u_{k}^{m}(Q) \mathrm{d} S+n_{j}(P) \int_{S} D_{k i j}(P, Q) \Delta t_{k}^{m}(Q) \mathrm{d} S
$$

where $\Delta u_{i}$ and $\Delta t_{i}$ are the incremental displacements and tractions, respectively. The total displacements and tractions after $m$ increments are

$$
\begin{aligned}
& u_{i}^{m}=u_{i}^{m-1}+\Delta u_{i}^{m}=\sum_{k=1}^{m} \Delta u_{i}^{k} \\
& t_{i}^{m}=t_{i}^{m-1}+\Delta t_{i}^{m}=\sum_{k=1}^{m} \Delta t_{i}^{k}
\end{aligned}
$$

The incremental boundary element formulation is

$$
[H]\left\{\Delta u^{m}\right\}=[G]\left\{\Delta t^{m}\right\}
$$

where $\left\{\Delta u^{m}\right\}$ and $\left\{\Delta t^{m}\right\}$ are vectors containing the incremental nodal displacements and tractions, respectively.

\subsection{Contact problem}

There are three different contact modes: stick, slip and separation. A Coulomb friction law, with a single friction coefficient $\mu$, is used as the interface constitutive relationship. The stick and slip modes depend on $\mu$, the tangential traction $t_{\mathrm{t}}$, and the normal traction $t_{\mathrm{n}}$ at a node pair as follows: if

$$
\left|t_{\mathrm{t}}\right|<\mu\left|t_{\mathrm{n}}\right|
$$


the two nodes stick together and when

$$
\left|t_{\mathrm{t}}\right|=\mu\left|t_{\mathrm{n}}\right|
$$

a relative tangential slip may occur. The sign must be chosen so that $t_{\mathrm{t}}$ opposes the slide. The case

$$
\left|t_{\mathrm{t}}\right|>\mu\left|t_{\mathrm{n}}\right|
$$

is a nonacceptable situation.

In a two-dimensional boundary element problem, each node has four variables: two displacements and two tractions. Of these four, exactly two must be known for the problem to be solvable. In a contact problem, both the tractions and displacements in the assumed contact area are unknown, and for two nodes forming a contact pair, there are eight unknowns but only four equations. However, if the contact type is known, coupling equations can be formed and the number of unknowns reduces to four.

Table I gives the relationships of incremental tractions and displacements of the contact node pair $a-b$ shown in Figure 3. These relationships are modified from those defined by Man et al. ${ }^{14}$ From Table I it can be observed that for each contact mode there are only four unknowns and therefore the number of equations equals the number of unknowns. Table II lists the boundary values that are chosen as the unknowns. This procedure is explained in detail by Tuhkuri. ${ }^{23}$ As an example, when the nodes $a$ and $b$ (Figure 3) are in slip mode at an increment $m$, the tractions $\Delta t_{\mathrm{n}}^{a}, \Delta t_{\mathrm{n}}^{b}$ and $\Delta t_{\mathrm{t}}^{b}$ are written as functions of $\Delta t_{\mathrm{t}}^{a}$. The traction vector of equation (12) is then

Table I. Modes of contact. The subscripts $\mathrm{t}$ and $\mathrm{n}$ refer to tangential and normal directions, respectively. The superscripts $a$ and $b$ refer to the nodes $a$ and $b$ (Figure 3), and $m$ and $m-1$ to load increments. $\mu$ is friction coefficient and the sign must be chosen so that $t_{\mathrm{t}}$ opposes the slide

\begin{tabular}{ccc}
\hline \multicolumn{1}{c}{ Stick } & Slip & Separation \\
\hline$\Delta\left(t_{\mathrm{t}}^{a}\right)^{m}-\Delta\left(t_{\mathrm{t}}^{b}\right)^{m}=0$ & $\Delta\left(t_{\mathrm{t}}^{a}\right)^{m}-\Delta\left(t_{\mathrm{t}}^{b}\right)^{m}=0$ & $\Delta\left(t_{\mathrm{t}}^{a}\right)^{m}=-\left(t_{\mathrm{t}}^{a}\right)^{m-1}$ \\
$\Delta\left(t_{\mathrm{n}}^{a}\right)^{m}-\Delta\left(t_{\mathrm{n}}^{b}\right)^{m}=0$ & $\Delta\left(t_{\mathrm{n}}^{a}\right)^{m}-\Delta\left(t_{\mathrm{n}}^{b}\right)^{m}=0$ & $\Delta\left(t_{\mathrm{n}}^{a}\right)^{m}=-\left(t_{\mathrm{n}}^{a}\right)^{m-1}$ \\
$\Delta\left(u_{\mathrm{t}}^{a}\right)^{m}+\Delta\left(u_{\mathrm{t}}^{b}\right)^{m}=0$ & $\Delta\left(t_{\mathrm{t}}^{a}\right)^{m} \pm \mu \Delta\left(t_{\mathrm{n}}^{a}\right)^{m}=$ & $\Delta\left(t_{\mathrm{t}}^{b}\right)^{m}=-\left(t_{\mathrm{t}}^{a}\right)^{m-1}$ \\
& $-\left[\left(t_{\mathrm{t}}^{a}\right)^{m-1} \pm \mu\left(t_{\mathrm{n}}^{a}\right)^{m-1}\right]$ & \\
$\Delta\left(u_{\mathrm{n}}^{a}\right)^{m}+\Delta\left(u_{\mathrm{n}}^{b}\right)^{m}=$ & $\Delta\left(u_{\mathrm{n}}^{a}\right)^{m}+\Delta\left(u_{\mathrm{n}}^{b}\right)^{m}=$ & $\Delta\left(t_{\mathrm{n}}^{b}\right)^{m}=-\left(t_{\mathrm{n}}^{a}\right)^{m-1}$ \\
$-\left[\left(u_{\mathrm{n}}^{a}\right)^{m-1}+\left(u_{\mathrm{n}}^{b}\right)^{m-1}\right]$ & $-\left[\left(u_{\mathrm{n}}^{a}\right)^{m-1}+\left(u_{\mathrm{n}}^{b}\right)^{m-1}\right]$ \\
\hline
\end{tabular}

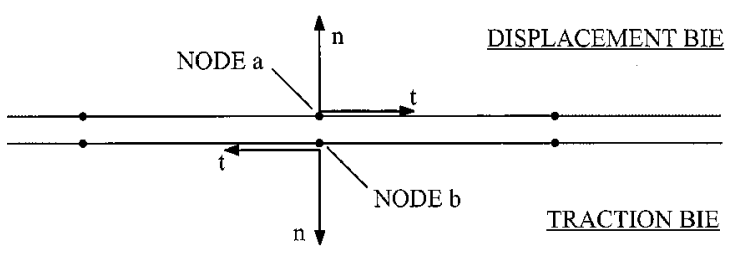

Figure 3. Two contact elements. The axes refer to the local normal (n) and tangential (t) directions 
Table II. The unknown boundary values at load increment $m$

\begin{tabular}{lccccc}
\hline \multicolumn{2}{c}{ Stick } & \multicolumn{2}{c}{ Slip } & \multicolumn{2}{c}{ Separation } \\
\hline Unknown & $\begin{array}{c}\text { Solved by } \\
\text { Table I }\end{array}$ & Unknown & $\begin{array}{c}\text { Solved by } \\
\text { Table I }\end{array}$ & Unknown & $\begin{array}{c}\text { Solved by } \\
\text { Table I }\end{array}$ \\
\hline$\Delta t_{\mathrm{t}}^{a}$ & $\Delta t_{\mathrm{t}}^{b}$ & $\Delta t_{\mathrm{t}}^{a}$ & $\Delta t_{\mathrm{n}}^{a}$ & $\Delta u_{\mathrm{t}}^{a}$ & $\Delta t_{\mathrm{t}}^{a}$ \\
$\Delta t_{\mathrm{n}}^{a}$ & $\Delta t_{\mathrm{n}}^{b}$ & $\Delta u_{\mathrm{n}}^{a}$ & $\Delta t_{\mathrm{t}}^{b}$ & $\Delta u_{\mathrm{n}}^{a}$ & $\Delta t_{\mathrm{n}}^{a}$ \\
$\Delta u_{\mathrm{t}}^{a}$ & $\Delta u_{\mathrm{t}}^{\mathrm{b}}$ & $\Delta u_{\mathrm{t}}^{a}$ & $\Delta t_{\mathrm{n}}^{b}$ & $\Delta u_{\mathrm{t}}^{b}$ & $\Delta t_{\mathrm{t}}^{b}$ \\
$\Delta u_{\mathrm{n}}^{a}$ & $\Delta u_{\mathrm{n}}^{b}$ & $\Delta u_{\mathrm{t}}^{b}$ & $\Delta u_{\mathrm{n}}^{b}$ & $\Delta u_{\mathrm{n}}^{b}$ & $\Delta t_{\mathrm{n}}^{b}$ \\
\hline
\end{tabular}

Table III. Examine modes of contact ${ }^{14}$

\begin{tabular}{|c|c|c|}
\hline \multirow[b]{2}{*}{ Assumption } & \multicolumn{2}{|c|}{ Decision } \\
\hline & Separate & Contact \\
\hline Separate & $\Delta\left(u_{\mathrm{n}}^{a}\right)^{m}+\Delta\left(u_{\mathrm{n}}^{b}\right)^{m}>0$ & $\Delta\left(u_{\mathrm{n}}^{a}\right)^{m}+\Delta\left(u_{\mathrm{n}}^{b}\right)^{m} \leqslant 0$ \\
\hline Contact & $\left(t_{\mathrm{n}}^{a}\right)^{m-1}+\Delta\left(t_{\mathrm{n}}^{a}\right)^{m} \leqslant 0$ & $\left(t_{\mathrm{n}}^{a}\right)^{m-1}+\left(t_{\mathrm{n}}^{a}\right)^{m}>0$ \\
\hline
\end{tabular}

written as

$$
\left\{\begin{array}{c}
\vdots \\
\Delta\left(t_{\mathrm{t}}^{a}\right)^{m} \\
\Delta\left(t_{\mathrm{n}}^{a}\right)^{m} \\
\vdots \\
\Delta\left(t_{\mathrm{t}}^{b}\right)^{m} \\
\Delta\left(t_{\mathrm{n}}^{b}\right)^{m} \\
\vdots
\end{array}\right\}=\left\{\begin{array}{c}
\vdots \\
\Delta\left(t_{\mathrm{t}}^{a}\right)^{m} \\
\mu^{-1} \Delta\left(t_{\mathrm{t}}^{a}\right)^{m} \\
\vdots \\
\Delta\left(t_{\mathrm{t}}^{a}\right)^{m} \\
\mu^{-1} \Delta\left(t_{\mathrm{t}}^{a}\right)^{m} \\
\vdots
\end{array}\right\}+\left\{\begin{array}{c}
\vdots \\
0 \\
-\mu^{-1}\left[\left(t_{\mathrm{t}}^{a}\right)^{m-1} \pm \mu\left(t_{\mathrm{n}}^{a}\right)^{m-1}\right] \\
\vdots \\
0 \\
-\mu^{-1}\left[\left(t_{\mathrm{t}}^{a}\right)^{m-1} \pm \mu\left(t_{\mathrm{n}}^{a}\right)^{m-1}\right] \\
\vdots
\end{array}\right\}=\left\{\Delta \bar{t}^{m}\right\}+\left\{\bar{t}^{m-1}\right\}
$$

Similar reasoning also holds for the displacement vector of equation (12). This equation can be written for the load increment $m$ as

$$
[H]\left\{\Delta \bar{u}^{m}\right\}+[H]\left\{\bar{u}^{m-1}\right\}=[G]\left\{\Delta \bar{t}^{m}\right\}+[G]\left\{\bar{t}^{m-1}\right\}
$$

Only the terms $\left\{\Delta \bar{u}^{m}\right\}$ and $\left\{\Delta \bar{t}^{m}\right\}$ contain unknowns and equation (17) can be put into the form

$$
[A]\left\{\Delta x^{m}\right\}=\left\{\Delta f^{m}\right\}+\left\{f^{m-1}\right\}
$$

where

$$
\left\{f^{m-1}\right\}=-[H]\left\{\bar{u}^{m-1}\right\}+[G]\left\{\bar{t}^{m-1}\right\}
$$

In order to solve equation (18) an initial contact mode is assumed, and after equation (18) is solved, a check is made to ensure that the assumed contact mode was the correct one. For example, if the stick mode is assumed, it is stated that the two contact nodes stay together. If the correct contact mode is separation, tensile stresses are observed between the two nodes. Then the assumed contact mode must be changed and a new iteration performed. The decisions on contact state are based on the Tables III and IV. ${ }^{14}$ For each iteration and for each contact node pair 
Table IV. Examine status of $\operatorname{contact}^{14}$

\begin{tabular}{|c|c|c|}
\hline \multirow[b]{2}{*}{ Assumption } & \multicolumn{2}{|c|}{ Decision } \\
\hline & Stick & Slip \\
\hline Stick & $\left|\left(t_{\mathrm{t}}^{a}\right)^{m-1}+\Delta\left(t_{\mathrm{t}}^{a}\right)^{m}\right| \leqslant\left|\mu\left[\left(t_{\mathrm{n}}^{a}\right)^{m-1}+\Delta\left(t_{\mathrm{n}}^{a}\right)^{m}\right]\right|$ & $\left|\left(t_{\mathrm{t}}^{a}\right)^{m-1}+\Delta\left(t_{\mathrm{t}}^{a}\right)^{m}\right|>\left|\mu\left[\left(t_{\mathrm{n}}^{a}\right)^{m-1}+\Delta\left(t_{\mathrm{n}}^{a}\right)^{m}\right]\right|$ \\
\hline Slip & {$\left[\left(t_{\mathrm{t}}^{b}\right)^{m-1}+\Delta\left(t_{\mathrm{t}}^{b}\right)^{m}\right] \cdot\left[\Delta\left(u_{\mathrm{t}}^{a}\right)+\Delta\left(u_{\mathrm{t}}^{b}\right)\right]>0$} & {$\left[\left(t_{\mathrm{t}}^{b}\right)^{m-1}+\Delta\left(t_{\mathrm{t}}^{b}\right)^{m}\right] \cdot\left[\Delta\left(u_{\mathrm{t}}^{a}\right)+\Delta\left(u_{\mathrm{t}}^{b}\right)\right] \leqslant 0$} \\
\hline
\end{tabular}

a first check is made using Table III to determine whether the nodes are in contact or not. If the nodes are in contact, then Table IV is used to determine whether the contact status is stick or slip.

\section{CALCULATION OF STRESS INTENSITY FACTORS}

\subsection{Displacement correlation method}

In the displacement correlation method ${ }^{4}$ the stress intensity factors are calculated from the displacements of opposite crack surfaces. Sih and Liebowitz ${ }^{24}$ considered the semi-infinite crack shown in Figure 4 and obtained equations for the displacements in the immediate vicinity of the crack tip. By assuming that the modes I and II are independent, the displacements are for a plane strain problem

$$
\begin{aligned}
& u_{1}=\frac{K_{\mathrm{I}}(1+v)}{2 E} \sqrt{\frac{r}{2 \pi}}\left[(2 \kappa-1) \cos \frac{\theta}{2}-\cos \frac{3 \theta}{2}\right]+\frac{K_{\mathrm{II}}(1+v)}{2 E} \sqrt{\frac{r}{2 \pi}}\left[(2 \kappa+3) \sin \frac{\theta}{2}+\sin \frac{3 \theta}{2}\right] \\
& u_{2}=\frac{K_{\mathrm{I}}(1+v)}{2 E} \sqrt{\frac{r}{2 \pi}}\left[(2 \kappa+1) \sin \frac{\theta}{2}-\sin \frac{3 \theta}{2}\right]-\frac{K_{\mathrm{II}}(1+v)}{2 E} \sqrt{\frac{r}{2 \pi}}\left[(2 \kappa-3) \cos \frac{\theta}{2}+\cos \frac{3 \theta}{2}\right]
\end{aligned}
$$

where $\kappa=3-4 v$. If the displacements of two points on the opposite crack surfaces are known, $K_{\mathrm{I}}$ and $K_{\mathrm{II}}$ can be solved by means of linear extrapolation with respect to $r$.

There is a limitation in using the displacement correlation method. When deriving equation (20), it was assumed that the crack surfaces are traction free, which is not the case if the crack is closed. However, as this method has been applied to closed cracks, ${ }^{16-18}$ it is used here also, but only as a secondary method. This problem of surface tractions can be avoided by using the $J$-integral method, which is used in this paper to calculate $K_{\mathrm{I}}$ and $K_{\mathrm{II}}$ unless stated otherwise.

\subsection{J-integral method}

The $J$-integral is a path independent integral around a crack tip ${ }^{25}$

$$
J=\int_{\Gamma}\left(W \mathrm{~d} x_{2}-t_{i} \frac{\partial u_{i}}{\partial x_{1}} \mathrm{~d} s\right)
$$

where $\mathrm{d} s$ is an element of path $\Gamma$ surrounding the crack tip (Figure 4), $t_{i}$ is a traction component, $u_{i}$ is a displacement component, and $W$ is strain energy density. If $n_{i}$ is a component of the unit outward normal of the path $\Gamma$, then $\mathrm{d} x_{2}=n_{1} \mathrm{~d} s$. The relationships between the $J$-integral, the 


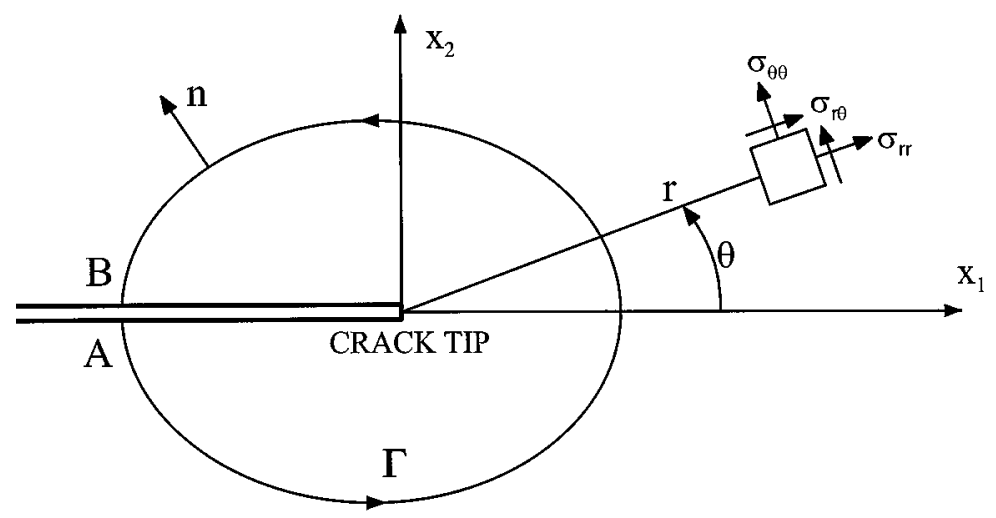

Figure 4. Crack tip stresses. Also an integration path $\Gamma$ for the $J$-integral is shown. The points $A$ and $B$ are on the lower and upper crack surfaces, respectively

energy release rate $G$, and the stress intensity factors for plane strain are ${ }^{25}$

$$
J=G=\frac{1-v^{2}}{E}\left(K_{\mathrm{I}}^{2}+K_{\mathrm{II}}^{2}\right)
$$

By decomposing the elastic field into symmetric and antisymmetric components with respect to the crack plane, the $J$-integral can be decomposed into modes I and II components, and the stress intensity factors for a plane strain case can be calculated from

$$
J_{\mathrm{M}}=\frac{1-v^{2}}{E} K_{\mathrm{M}}^{2}
$$

where $\mathrm{M}$ refers to the crack opening mode. ${ }^{26}$

However, if a crack tip is closed, the above procedure must be modified as the $J$-integral applies only when the crack surfaces are traction free. Following Palmer and Rice $^{27}$ it can be shown that

$$
G=J_{A B}-\left|t_{1}\right|\left|u_{1}^{B}-u_{1}^{A}\right|
$$

where $J_{A B}$ is the $J$-integral calculated by using a path from point $A$ on the lower crack surface to point $B$ on the upper crack surface (Figure 4 ), $t_{1}$ is the tangential traction on the crack surfaces, and $u_{1}^{A}$ and $u_{1}^{B}$ are tangential displacements of the points $A$ and $B$, respectively. In the derivation of equation (24), the normal components $t_{2}$, etc., also appear but cancel out when integrated along the two parts of the crack since $u_{2}$ is zero for a closed crack. Hence, what is left in equation (24) is a function only of the tangential slippage $u_{1}^{B}-u_{1}^{A}$, which is zero if and only if $K_{\mathrm{II}}$ is. Equation (24) can be obtained also directly from energy considerations as stated by $\mathrm{Li}^{28}{ }^{28} \mathrm{The} J$-integral can be interpreted as the energy sum of crack driving force and frictional dissipation. Now the crack driving force $G$ for a closed crack can be calculated with equation (24), and as $K_{\mathrm{I}}=0$ for a closed crack, no decoupling is needed and $K_{\mathrm{II}}$ is obtained from equation (22).

\section{FRACTURE CRITERIA AND PREDICTION OF CRACK PATH}

In a pure mode I case a crack can be assumed to propagate in the plane of the original crack when $K_{\mathrm{I}}$ reaches the fracture toughness $K_{\mathrm{IC}}$. However, for a mixed mode crack problem more 
comprehensive criteria are needed. Erdogan and $\mathrm{Sih}^{29}$ considered crack extension in plates and hypothesised that a crack will grow in the direction $\theta_{0}$ along which the tangential stress $\sigma_{\theta \theta}$ is maximum and the shear stress $\sigma_{r \theta}$ is zero (Figure 4). The direction of crack growth according to this hypothesis is

$$
K_{\mathrm{I}} \sin \theta_{0}+K_{\mathrm{II}}\left(3 \cos \theta_{0}-1\right)=0
$$

For pure modes I and II cases, equation (25) gives $\theta_{0}=0^{\circ}$ and $\theta_{0}= \pm 70 \cdot 5^{\circ}$, respectively. Both of these values have experimental support. ${ }^{29}$ Erdogan and $\mathrm{Sih}^{29}$ assumed further that crack extension initiates when $\sigma_{\theta \theta}$ reaches a critical value. Because it is assumed that $\sigma_{r \theta}$ is zero, that critical stress value can be related to the mode I fracture toughness. Then this mixed mode failure criterion states that a crack will propagate when

$$
\cos \frac{\theta_{0}}{2}\left[K_{\mathrm{I}} \cos ^{2} \frac{\theta_{0}}{2}-\frac{3}{2} K_{\mathrm{II}} \sin \theta_{0}\right] \geqslant K_{\mathrm{IC}}
$$

where the angle $\theta_{0}$ is obtained from equation (25). The left-hand side of equation (26) can be considered as an equivalent mode I stress intensity factor $K_{\text {IEQ }}$. It follows that a crack will advance if $K_{\mathrm{IEQ}} \geqslant K_{\mathrm{IC}}$.

This approach can be criticised because it is based on analysis of a straight crack while a growing crack under mixed mode loading will curve. For this reason both $\mathrm{Sih}^{30}$ and Hussain et al. ${ }^{31}$ have suggested new crack propagation criteria based on energy considerations. However, the differences between these criteria are not major, ${ }^{32}$ and what is more important, they all suggest that a crack will propagate to a direction that will minimise $\left|K_{\text {II }}\right|$. This is analogous to the principle of local symmetry suggested by Goldstein and Salganik. ${ }^{33}$

\section{NUMERICAL IMPLEMENTATION}

In short, equations (17) and (11) describe the incremental and iterative BE method developed. First the influence matrices $[H]$ and $[G]$ are formed based on the known initial geometry and the assumed contact conditions on the crack interfaces. Then equation (18) is formed and solved and the contact status is studied. If the assumed contact conditions are violated, the contact modes of those node pairs are changed, and a new equation (18) is formed and solved. This iteration is continued until an equilibrium is reached. After that each crack tip is checked to determine whether a fracture may occur. If $K_{\mathrm{IEQ}} \geqslant K_{\mathrm{IC}}$ a crack is advanced one preset increment to the direction $\theta_{0}$ calculated by equation (25). New elements are generated and the matrices $[H]$ and $[G]$ are reformed. If fracture does not occur, the next load increment is applied. The incremental loading and crack propagation is continued in this way until a predefined load value or crack length is reached.

In a general crack growth simulation model it is required to know how the loading changes during the crack growth. However, in the present model it is assumed, for simplicity, that the loading (imposed tractions or displacements) is monotonically increasing. The cracks for which $K_{\text {IEQ }} \geqslant K_{\text {IC }}$ will advance and the loading will stay constant.

The calculated crack growth is approximate in the sense that it models a curved crack path with straight increments of equal length. In some problems the calculated path has been observed to oscillate about an average path because of inaccuracies in $K_{\mathrm{II}}$ and $\theta .^{32}$ One such case is the simulation of wing crack growth shown in the next section. This problem can be overcome by searching for a path that minimises $\left|K_{\text {II }}\right|$, which is just the principle of local symmetry. ${ }^{33}$ 
Even though the contact conditions are analysed for each node pair, only one contact state is accepted for each element. If this was not the case, incompatibilities may occur. ${ }^{12}$ After the nodal contact conditions are solved, the total traction on an element in contact is calculated. If this total traction is tensile, then the two elements are treated as separate. If the traction is compressive, then the elements are treated to be either in stick or slip mode. As there are three nodes in each element, the element is in stick mode if two or three nodes are in stick mode. Otherwise the whole element is in slip mode. This convergence criterion means in physical terms that traction discontinuities are accepted but overlapping crack surfaces are not accepted.

The convergence problems have been solved by many researchers by load scaling ${ }^{13,14}$ where each load increments is scaled in such a way that the contact border is always at an end node of an element. However, the load scaling method can be used only in problems where the extent of contact is load dependent. Unfortunately, many problems dealing with straight cracks are contact problems of two conforming surfaces and the contact area is load independent. The areas of stick and slip can still be load dependent.

\section{NUMERICAL EXAMPLES}

\subsection{Mixed mode crack in an infinite plate}

Figure 5(a) shows a crack with length $2 a$ in an infinite plate under remote compressive and shear stresses. An analytical solution for $K_{\mathrm{II}}$ is ${ }^{34}$

$$
K_{\mathrm{II}}=\sqrt{\pi a}\left(\tau-\mu_{\mathrm{c}} \sigma\right)
$$

Table V shows the results obtained by equation (27) and by the present BE code. The $K_{\text {II }}$ values calculated using the $J$-integral method are very close to the analytical results. The $K_{\text {II }}$ values

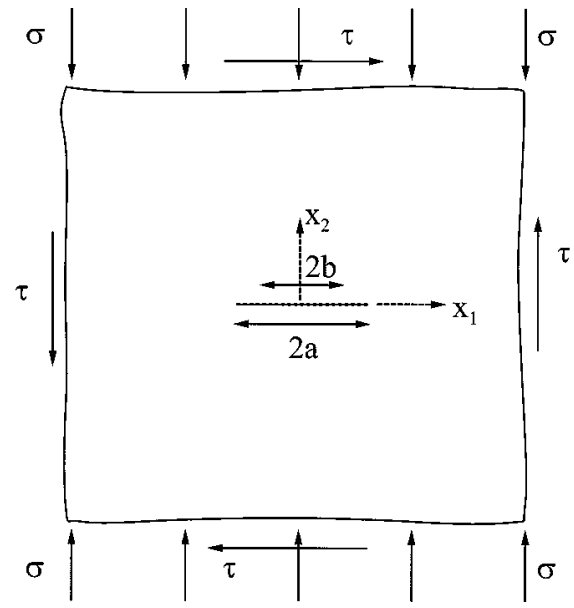

(a)

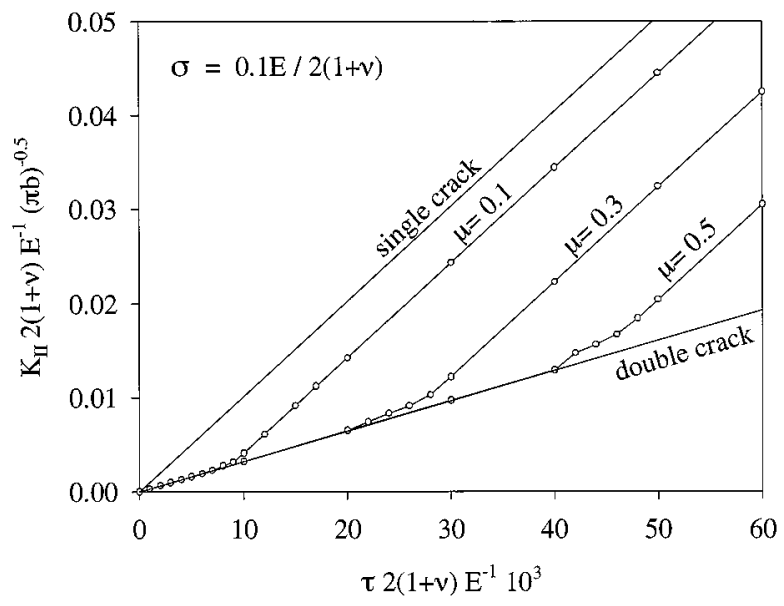

(b)

Figure 5. (a) A crack of length $2 a$ with a symmetric contact region of length $2 b$ in an infinite plate under a mixed mode loading. (b) Calculated stress intensity factors for the case $b / a=0 \cdot 8$ 
Table V. Mode II stress intensity factor for a mixed mode crack of length $2 a$ in an infinite plate shown in Figure 5(a). $b=a, \sigma=2 \tau, v=0.3$

\begin{tabular}{|c|c|c|c|}
\hline$\mu_{\mathrm{c}}$ & $\begin{array}{l}\text { Equation (27) } \\
\qquad \frac{K_{\mathrm{II}}}{\tau \sqrt{\pi a}}\end{array}$ & $\begin{array}{c}\text { BEM } \\
J \text {-integral method } \\
\frac{K_{\mathrm{II}}}{\tau \sqrt{\pi a}}\end{array}$ & $\begin{array}{c}\text { BEM } \\
\text { Displacement } \\
\text { correlation method } \\
\frac{K_{\mathrm{II}}}{\tau \sqrt{\pi a}}\end{array}$ \\
\hline 0.0 & $1 \cdot 000$ & 1.008 & $1 \cdot 089$ \\
\hline $0 \cdot 1$ & $0 \cdot 800$ & $0 \cdot 805$ & $0 \cdot 871$ \\
\hline $0 \cdot 2$ & 0.600 & 0.602 & 0.654 \\
\hline $0 \cdot 3$ & $0 \cdot 400$ & 0.402 & 0.436 \\
\hline $0 \cdot 4$ & $0 \cdot 200$ & $0 \cdot 199$ & $0 \cdot 218$ \\
\hline $0 \cdot 5$ & 0.000 & $0 \cdot 013$ & $0 \cdot 001$ \\
\hline
\end{tabular}

obtained using the displacement correlation method are about 9 per cent larger than the analytical results, but this difference is consistent. It was verified that these results are not sensitive to the number of elements used or to the dimensions of the mesh. It was further verified that the initial contact state has no effect on the final result.

Selvadurai ${ }^{35}$ has analysed with a BE method a more complicated case of a mixed mode crack in an infinite plate. He studied the problem where a crack of length $2 a$ has a symmetric contact region of length $2 b$ as shown in Figure 5(a). The compressive stress $\sigma$ is assumed to have a constant value, while the shear stress $\tau$ is gradually increasing. Figure 5(b) shows the calculated non-linear relationships between $\tau$ and $K_{\text {II }}$ as a function of the friction coefficient. The computed values of $K_{\mathrm{II}}$ for the limiting cases of a single crack $(\mu=0)$ and a double crack $(\mu \rightarrow \infty)$, are identical to those obtained by Selvadurai. ${ }^{35}$ Also, when $\mu$ has an intermediate value, both analyses identify regions of stick, partial slip and finally full slip. However, the present model predicts a higher $\tau$ for the onset of slip. This is believed to be due to the different interface models used. Selvadurai ${ }^{35}$ considered an interface that follows the constitutive law: $t_{i}=k_{i j} \Delta u_{j}$. In the present $\mathrm{BE}$ formulation, the crack interface is rigid when the crack is closed and does not slip. In both models it is assumed that once slip occurs, the normal and tangential tractions are related by the Coulomb friction law.

\subsection{Radial crack emanating from a circular hole}

The second example considers a radial crack emanating from a circular hole as shown in Figure 6. It is assumed that the hole and the crack are in an infinite sheet either under uniform tension along the $x_{1}$-axis or under inplane shear. Depending on the crack length $a$ and inclination angle $\alpha$ parts of the crack can be open or closed and the closed region can have zones of stick and slip. In the case of uniform inplane shear, the crack remains completely closed when $\alpha=0$. The calculated results for the frictionless case are given in Table VI, which shows that the present results are equal with those given by $\mathrm{Hsu}^{36}$ and by Comninou and Chang. ${ }^{37}$ Note that Comninou and Chang ${ }^{37}$ used different notation than used here and that it is assumed that there is a misprint in their paper where $\pi$ is missing under the square root. Considering then the case of a remote uniform tensile load along the $x_{1}$-axis, Table VII gives the results for the case of constant crack 


$\begin{array}{ll}\text { Zone of contact: } & 0<x_{c}<c \\ \text { Zone of stick: } & 0<x_{c}<b \\ \text { Zone of slip: } & b<x_{c}<c \\ \text { Zone of separation: } c<x_{c}<a\end{array}$

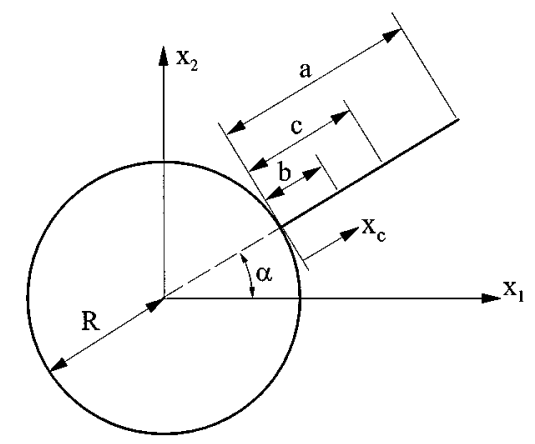

Figure 6. A radial crack of length a emanating from a circular hole in an infinite plate

Table VI. Stress intensity factors for the crack in Figure 6 under a uniform inplane shear of magnitude $\tau . \alpha=0$, $\mu=0$

\begin{tabular}{|c|c|c|c|}
\hline$a / R$ & $\begin{array}{l}\text { Present results } \\
\qquad \frac{K_{\mathrm{II}}}{\tau \sqrt{\pi a}}\end{array}$ & $\begin{array}{l}\mathrm{Hsu}^{36} \\
\frac{K_{\mathrm{II}}}{\tau \sqrt{\pi a}}\end{array}$ & $\begin{array}{c}\text { Comninou and } \\
\text { Chang }^{37} \\
\frac{K_{\mathrm{II}}}{\tau \sqrt{\pi a}}\end{array}$ \\
\hline 0.5 & 1.090 & 1.086 & $1 \cdot 085$ \\
\hline $1 \cdot 0$ & $1 \cdot 205$ & $1 \cdot 200$ & $1 \cdot 201$ \\
\hline $1 \cdot 5$ & $1 \cdot 180$ & $1 \cdot 176$ & $1 \cdot 177$ \\
\hline $2 \cdot 0$ & $1 \cdot 136$ & $1 \cdot 132$ & $1 \cdot 132$ \\
\hline $5 \cdot 0$ & 0.954 & 0.948 & 0.948 \\
\hline
\end{tabular}

Table VII. Stress intensity factors for the crack in Figure 6 under a remote uniform tensile load along $x_{1}$-axis of magnitude $\sigma \cdot a / R=3, \mu=0 \cdot 5, c^{*}=\pi(a-c) / 2$, $b^{*}=\pi(a-b) / 2$

\begin{tabular}{|c|c|c|c|c|c|c|c|c|}
\hline \multirow[b]{3}{*}{$\alpha$} & \multicolumn{4}{|c|}{ Present results } & \multicolumn{4}{|c|}{ Comninou and Chang ${ }^{37}$} \\
\hline & & & $K_{\mathrm{I}}$ & $\left|K_{\mathrm{II}}\right|$ & & & $K_{\mathrm{I}}$ & $\left|K_{\mathrm{II}}\right|$ \\
\hline & $b / R$ & $c / R$ & $\sigma \sqrt{c^{*}}$ & $\sigma \sqrt{b^{*}}$ & $b / R$ & $c / R$ & $\sigma \sqrt{c^{*}}$ & $\sigma \sqrt{b^{*}}$ \\
\hline 1 & $0 \cdot 30$ & $0 \cdot 60$ & $0 \cdot 030$ & $0 \cdot 024$ & $0 \cdot 270$ & $0 \cdot 470$ & 0.031 & 0.021 \\
\hline 4 & $0 \cdot 15$ & 0.45 & 0.034 & $0 \cdot 088$ & 0.031 & 0.438 & $0 \cdot 036$ & 0.086 \\
\hline 6 & 0 & 0.45 & $0 \cdot 041$ & $0 \cdot 139$ & 0 & 0.398 & $0 \cdot 042$ & $0 \cdot 136$ \\
\hline 10 & 0 & $0 \cdot 30$ & $0 \cdot 060$ & $0 \cdot 256$ & 0 & $0 \cdot 292$ & $0 \cdot 061$ & $0 \cdot 240$ \\
\hline 15 & 0 & $0 \cdot 15$ & 0.099 & $0 \cdot 374$ & 0 & $0 \cdot 140$ & $0 \cdot 100$ & $0 \cdot 366$ \\
\hline 20 & 0 & 0 & $0 \cdot 159$ & $0 \cdot 480$ & 0 & 0 & $0 \cdot 150$ & 0.469 \\
\hline
\end{tabular}


length and changing inclination. Zones of stick, slip and separation were found to be similar to the earlier studies. No optimisation of element division was performed, as $K_{\text {II }}$ seemed not to be very sensitive to the value of $c / R$.

\subsection{Growth of wing cracks}

The third example illustrates the crack propagation capabilities of the method. Ashby and Hallam $^{38,39}$ have studied experimentally the growth of wing cracks in a brittle plate (PMMA). In the tests a plate with an initial inclined flaw was compressed as shown in Figure 7(a). The load needed to propagate the wing cracks is given in Figure 7(b) which illustrates that the wing crack growth was stable after an initial unstable phase. However, $\mathrm{d} \sigma / \mathrm{d} a_{\mathrm{w}}$ is decreasing with increasing

(a)
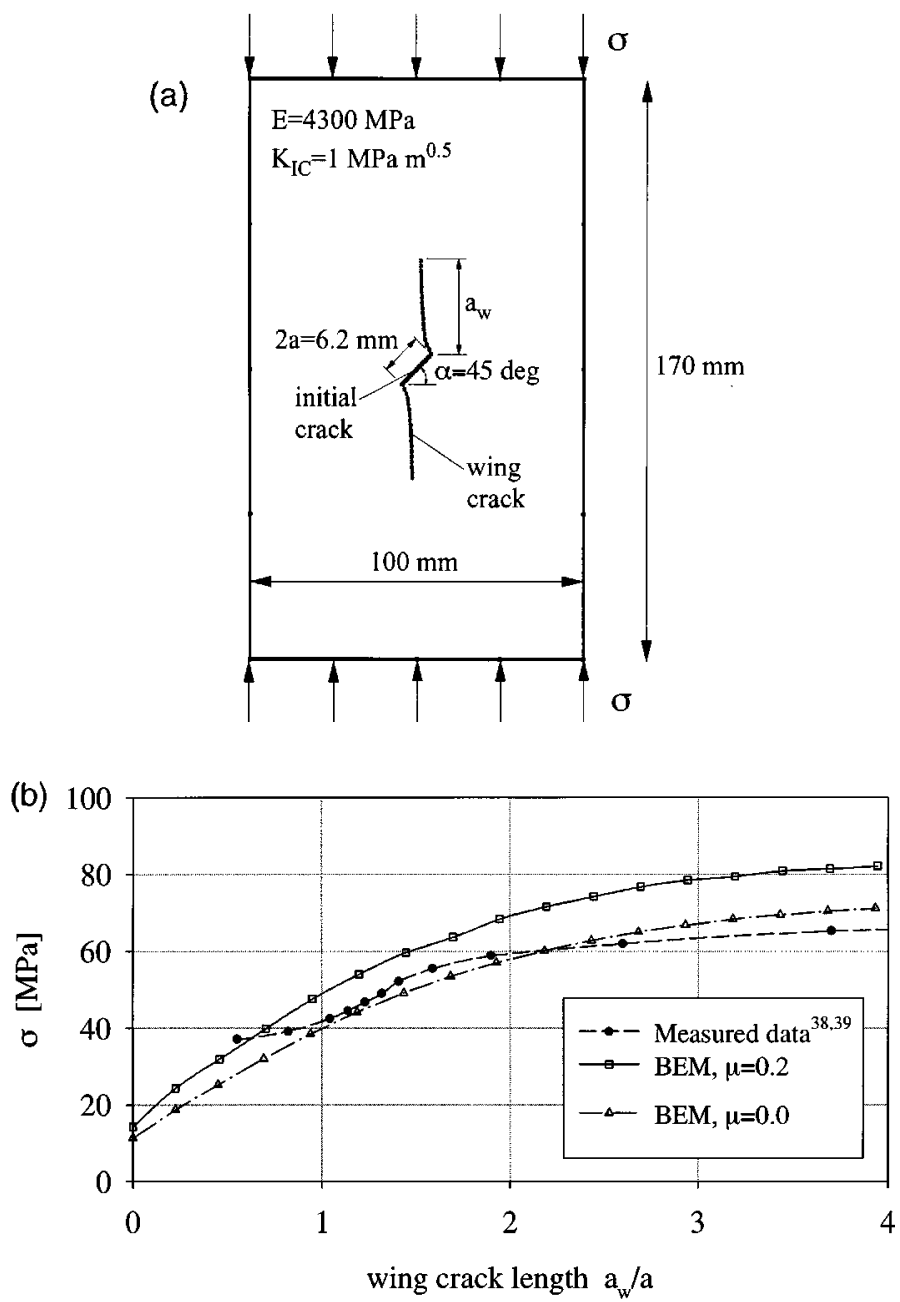

Figure 7. (a) Calculated growth of wing cracks of length $a_{\mathrm{w}}$ from an initial flaw of length $2 a$ and inclination $\alpha$. The dimensions and material values are those used in tests by Ashby and Hallam. ${ }^{38,39}$ The growth increment used was $\Delta a=a / 4$. (b) The load needed to propagate the crack 
$a_{\mathrm{w}}$ suggesting that the growth may become unstable again when the wing cracks are long. Figure 7(b) also gives the computational results, which are similar to the measured ones, except that initial unstable growth is not captured by the model. Cooksley ${ }^{39}$ has reported all the data needed for the calculations, except the friction coefficient $\mu$ at the crack interface. In the tests two brass shims were inserted into the slot to ensure contact between the two crack surfaces.

\section{SUMMARY AND CONCLUSIONS}

A dual BE method to analyse closed cracks has been developed and formulated into a computer code. This method is an extension of the method developed by Portela et al. ${ }^{6-9}$ for analysis of two-dimensional fracture mechanics problems where it is assumed that the cracks are open. The present work extends their formulation by allowing non-zero normal and frictional tractions at the crack surfaces and hence the analysis of closed cracks. The analysis of closed cracks is analogous to a contact mechanics problem of two elastic bodies in contact. As such a problem is non-linear, it was formulated in an incremental and iterative fashion. The dual BEM turned out to be well suited for the analysis of two-dimensional contact mechanics problems and closed cracks with frictional surfaces. The computational method developed gave stress intensity factors and contact areas similar to those given in the literature. Also the growth of cracks was simulated. The computed path of growing wing cracks and the load needed to propagate these cracks were similar to those measured during experiments.

\section{APPENDIX}

Calculation of the influence matrices $[H]$ and $[G]$

If the boundary is divided into $N$ quadratic elements, the displacement BIE (equation (1)) can approximated with the equation

$\frac{1}{2}\left\{\begin{array}{l}u_{1}(P) \\ u_{2}(P)\end{array}\right\}=-\sum_{j=1}^{N}\left\{\int_{-1}^{1}\left[\begin{array}{ll}T_{11} & T_{12} \\ T_{21} & T_{22}\end{array}\right][\Phi]|J| \mathrm{d} \xi\right\}\left\{u^{j}\right\}+\sum_{j=1}^{N}\left\{\int_{-1}^{1}\left[\begin{array}{ll}U_{11} & U_{12} \\ U_{21} & U_{22}\end{array}\right][\Phi]|J| \mathrm{d} \xi\right\}\left\{t^{j}\right\}$

where the matrix $[\Phi]$ contains the shape functions, $|J|$ is the Jacobian, $\xi$ is a dimensionless local co-ordinate, $-1 \leqslant \xi \leqslant 1$, and the vectors $\left\{u^{j}\right\}$ and $\left\{t^{j}\right\}$ contain the nodal displacements and tractions. ${ }^{1,2}$ In a similar way the boundary element approximation of the traction BIE (equation (4)) is

$$
\begin{aligned}
\frac{1}{2}\left\{\begin{array}{l}
t_{1}(P) \\
t_{2}(P)
\end{array}\right\}= & -\sum_{j=1}^{N}\left\{\int_{-1}^{1}\left[\begin{array}{ll}
n_{1} S_{111}+n_{2} S_{121} & n_{1} S_{211}+n_{2} S_{221} \\
n_{1} S_{112}+n_{2} S_{122} & n_{1} S_{212}+n_{2} S_{222}
\end{array}\right][\Phi]|J| \mathrm{d} \xi\right\}\left\{u^{j}\right\} \\
& +\sum_{j=1}^{N}\left\{\int_{-1}^{1}\left[\begin{array}{ll}
n_{1} D_{111}+n_{2} D_{121} & n_{1} D_{211}+n_{2} D_{221} \\
n_{1} D_{112}+n_{2} D_{122} & n_{1} D_{212}+n_{2} D_{222}
\end{array}\right][\Phi]|J| \mathrm{d} \xi\right\}\left\{t^{j}\right\}
\end{aligned}
$$


Therefore, calculation of the influence matrix $[H]$ includes the integrations

$$
\begin{gathered}
\int_{-1}^{1} T_{i j} \phi_{k}|J| \mathrm{d} \xi \\
\int_{-1}^{1} n_{m} S_{k i j} \phi_{q}|J| \mathrm{d} \xi
\end{gathered}
$$

and calculation of the influence matrix $[G]$ includes the integrations

$$
\begin{gathered}
\int_{-1}^{1} U_{i j} \phi_{k}|J| \mathrm{d} \xi \\
\int_{-1}^{1} n_{m} D_{k i j} \phi_{q}|J| \mathrm{d} \xi
\end{gathered}
$$

These integrals can be calculated by using the Gaussian quadrature except when the field point approaches the collocation point $(r \rightarrow 0)$, as there are singularities in the fundamental solutions. Integration of $U_{i j}$ and $T_{i j}$ when $r=0$ is a standard problem: ${ }^{1,2}$ Logarithmic Gaussian quadrature is used to integrate $U_{i j}$ and rigid body considerations to calculate $T_{i j}$.

However, additional complications arise in the dual $\mathrm{BE}$ formulation where integrations of $D_{k i j}$ and $S_{k i j}$ are needed in the traction boundary integral equation. The singularity subtraction method $^{6}$ can be used to handle the singularity problem, but the task can be simplified considerably by assuming that the crack elements are straight. Then the integrals containing singularities can be performed analytically. Portela et al. ${ }^{6}$ integrated analytically the singular integrals in $[H]$ but as they assumed that the cracks are traction free they did not need the singular integrals in $[G]$ at all. In this appendix the singular integrals in $[G]$ are formed and, for completeness, the singular integrals in $[H]$ are given also.

Singular integrals in the matrix $[H]$ when the collocation point is a crack node

In the present formulation the crack elements (Figure 2) are discontinuous, and hence $r$ can be zero only when the collocation node and the field node are in the same element, or the other is in the opposite crack element. Further, as the crack elements are straight: $r_{, 1}=\cos \theta, r_{, 2}=\sin \theta$, $n_{1}=\sin \theta, n_{2}=-\cos \theta, \partial r / \partial n=0$, and $|J|=L / 2$. Equation (30) can now be written as

$$
\int_{-1}^{1} T_{i j} \phi_{k}|J| \mathrm{d} \xi=\left(n_{i} r_{, j}-n_{j} r_{, i}\right) \frac{1-2 v}{4 \pi(1-v)} \int_{-1}^{1} \frac{\phi_{k}}{\left|\xi-\xi^{\prime}\right|} \mathrm{d} \xi
$$

where $\xi^{\prime}$ is the collocation point, $\xi$ is the field point, and it has been taken into account that $r=\left|\xi^{\prime}-\xi\right| L / 2 . \phi_{k}(\xi)$ are the shape functions of the discontinuous element (Figure 2): ${ }^{6}$

$$
\begin{aligned}
& \phi_{1}=\xi\left(\frac{9}{8} \xi-\frac{3}{4}\right) \\
& \phi_{2}=\left(1-\frac{3}{4} \xi\right)\left(1+\frac{3}{4} \xi\right) \\
& \phi_{3}=\xi\left(\frac{9}{8} \xi+\frac{3}{4}\right)
\end{aligned}
$$


The integrals in equation (35) can be integrated analytically ${ }^{40}$ to give

$$
\begin{aligned}
& \int_{-1}^{1} \frac{\phi_{1}}{\left|\xi-\xi^{\prime}\right|} \mathrm{d} \xi=\frac{3}{4}\left[\frac{\xi^{\prime}\left(3 \xi^{\prime}-2\right)}{2} \ln \frac{\left|\xi-\xi^{\prime}\right|}{\left|\xi+\xi^{\prime}\right|}+3 \xi^{\prime}-2\right] \\
& \int_{-1}^{1} \frac{\phi_{2}}{\left|\xi-\xi^{\prime}\right|} \mathrm{d} \xi=\frac{1}{2}\left[\frac{\left(3 \xi^{\prime}-2\right)\left(3 \xi^{\prime}+2\right)}{2} \ln \frac{\left|\xi-\xi^{\prime}\right|}{\left|\xi+\xi^{\prime}\right|}-9 \xi^{\prime}\right] \\
& \int_{-1}^{1} \frac{\phi_{3}}{\left|\xi-\xi^{\prime}\right|} \mathrm{d} \xi=\frac{3}{4}\left[\frac{\xi^{\prime}\left(3 \xi^{\prime}+2\right)}{2} \ln \frac{\left|\xi-\xi^{\prime}\right|}{\left|\xi+\xi^{\prime}\right|}+3 \xi^{\prime}+2\right]
\end{aligned}
$$

In a similar manner, equation (31) reduces to

$$
n_{m} \int_{-1}^{1} S_{k i j} \phi_{q}|J| \mathrm{d} \xi=n_{m} \frac{E}{4 \pi\left(1-v^{2}\right)} \frac{2}{L} S_{k i j}\left(n_{1}, n_{2}\right) \int_{-1}^{1} \frac{\phi_{q}}{\left(\xi-\xi^{\prime}\right)^{2}} \mathrm{~d} \xi
$$

where

$$
\begin{aligned}
& s_{111}=n_{1}\left(2 n_{2}^{2}+1\right) \\
& s_{112}=s_{121}=n_{2}\left(-2 n_{1}^{2}+1\right) \\
& s_{211}=n_{2}\left(2 n_{2}^{2}-1\right) \\
& s_{222}=n_{2}\left(2 n_{1}^{2}+1\right) \\
& s_{221}=s_{212}=n_{1}\left(-2 n_{2}^{2}+1\right) \\
& s_{122}=n_{1}\left(2 n_{1}^{2}-1\right)
\end{aligned}
$$

The integrals in equation (38) can be integrated analytically. ${ }^{40}$ These integrals are:

$$
\begin{aligned}
& \int_{-1}^{1} \frac{\phi_{1}}{\left(\xi-\xi^{\prime}\right)^{2}} \mathrm{~d} \xi=\frac{3}{4}\left[(3 \xi-1) \ln \frac{\left|1-\xi^{\prime}\right|}{|1+\xi|}+\frac{6 \xi^{\prime 2}-2 \xi^{\prime}-3}{\xi^{\prime 2}-1}\right] \\
& \int_{-1}^{1} \frac{\phi_{2}}{\left(\xi-\xi^{\prime}\right)^{2}} \mathrm{~d} \xi=\frac{1}{2}\left[9 \xi \ln \frac{\left|1+\xi^{\prime}\right|}{|1-\xi|}-\frac{18 \xi^{\prime 2}-13}{\xi^{\prime 2}-1}\right] \\
& \int_{-1}^{1} \frac{\phi_{3}}{\left(\xi-\xi^{\prime}\right)^{2}} \mathrm{~d} \xi=\frac{3}{4}\left[(3 \xi+1) \ln \frac{\left|1-\xi^{\prime}\right|}{|1+\xi|}+\frac{6 \xi^{\prime 2}+2 \xi^{\prime}-3}{\xi^{\prime 2}-1}\right]
\end{aligned}
$$

Singular integrals in the matrix $[G]$ when the collocation point is a crack node

For a discontinuous straight element (Figure 2) equation (32) can be written as

$$
\begin{aligned}
\int_{-1}^{1} U_{i j} \phi_{k}|J| \mathrm{d} \xi= & -\frac{(1+v) L}{8 \pi E(1-v)}(3-4 v) \delta_{i j} \int_{-1}^{1} \ln \left|\xi-\xi^{\prime}\right| \phi_{k} \mathrm{~d} \xi \\
& -\frac{(1+v) L}{8 \pi E(1-v)}\left[(3-4 v) \delta_{i j} \ln \frac{L}{2}-r_{, i} r_{, j}\right] \int_{-1}^{1} \phi_{k} \mathrm{~d} \xi
\end{aligned}
$$


Equation (41) contains two types of integrals and both types easily can be integrated analytically. ${ }^{40}$ The results are:

$$
\begin{aligned}
\int_{-1}^{1} \phi_{1} \ln \left|\xi-\xi^{\prime}\right| \mathrm{d} \xi= & \frac{3}{8}\left[\ln \left(1-\xi^{\prime 2}\right)-\left(\xi^{\prime 3}-\xi^{\prime 2}+1\right) \ln \frac{\left|1-\xi^{\prime}\right|}{\left|1+\xi^{\prime}\right|}-2\left(\xi^{\prime 2}-\xi^{\prime}+\frac{1}{3}\right)\right] \\
\int_{-1}^{1} \phi_{2} \ln \left|\xi-\xi^{\prime}\right| \mathrm{d} \xi= & \frac{1}{4}\left[\ln \left(1-\xi^{\prime 2}\right)-\xi^{\prime}\left(3 \xi^{\prime 2}-4\right) \ln \frac{\left|1-\xi^{\prime}\right|}{\left|1+\xi^{\prime}\right|}-6\left(1-\xi^{\prime 2}\right)\right] \\
\int_{-1}^{1} \phi_{3} \ln \left|\xi-\xi^{\prime}\right| \mathrm{d} \xi=\frac{3}{8} & {\left[\ln \left(1-\xi^{\prime 2}\right)-\left(\xi^{\prime 3}+\xi^{\prime 2}-1\right) \ln \frac{\left|1-\xi^{\prime}\right|}{\left|1+\xi^{\prime}\right|}-2\left(\xi^{\prime 2}+\xi^{\prime}+\frac{1}{3}\right)\right] } \\
& \int_{-1}^{1} \phi_{1} \mathrm{~d} \xi=\int_{-1}^{1} \xi\left(\frac{9}{8} \xi-\frac{3}{4}\right) \mathrm{d} \xi=\frac{3}{4} \\
& \int_{-1}^{1} \phi_{2} \mathrm{~d} \xi=\int_{-1}^{1}\left(1-\frac{3}{4} \xi\right)\left(1+\frac{3}{4} \xi\right) \mathrm{d} \xi=\frac{1}{2} \\
& \int_{-1}^{1} \phi_{3} \mathrm{~d} \xi=\int_{-1}^{1} \xi\left(\frac{9}{8} \xi+\frac{3}{4}\right) \mathrm{d} \xi=\frac{3}{4}
\end{aligned}
$$

The last type of singular integrals be calculated are those of the type given in equation (33). That equation can be put into the form

$$
\int_{-1}^{1} n_{m} D_{k i j} \phi_{q}|J| \mathrm{d} \xi=n_{m} \frac{1}{4 \pi(1-v)} d_{k i j}\left(n_{1}, n_{2}\right) \int_{-1}^{1} \frac{\phi_{q}}{\left|\xi-\xi^{\prime}\right|} \mathrm{d} \xi
$$

where

$$
\begin{aligned}
& d_{111}=-(1-2 v) n_{2}-2 n_{2}^{3} \\
& d_{211}=-(1-2 v) n_{1}-2 n_{2}^{2} n_{1} \\
& d_{122}=(1-2 v) n_{2}-2 n_{1}^{2} n_{2} \\
& d_{222}=(1-2 v) n_{1}+2 n_{1}^{3} \\
& d_{121}=d_{112}=(1-2 v) n_{1}+2 n_{2}^{2} n_{1} \\
& d_{221}=d_{212}=-(1-2 v) n_{2}+2 n_{1}^{2} n_{2}
\end{aligned}
$$

The integrals in equation (44) were already given in equation (37).

\section{ACKNOWLEDGEMENTS}

The author would like to thank Professors Petri Varsta and Kaj Riska of the Helsinki University of Technology, Professor A. P. S. Selvadurai of McGill University, and Dr. M. H. Aliabadi of the Wessex Institute of Technology for their advice and support. This work was funded by the Academy of Finland. 


\section{REFERENCES}

1. C. A. Brebbia and J. Dominquez, Boundary Elements, An Introductory Course, Computational Mechanics Publications, Southampton, 1989.

2. A. A. Becker, The Boundary Element Method in Engineering, McGraw-Hill, London, 1992.

3. S. L. Crouch and A. M. Starfield, Boundary Element Methods in Solid Mechanics, Unvin Hyman, London, 1990.

4. G. E. Blandford, A. R. Ingraffea and J. A. Liggett, 'Two-dimensional stress intensity factor computations using the boundary element method', Int. J. Numer. Meth. Engng., 17, 387-404 (1981).

5. H. K. Hong and J.-T. Chen, 'Derivations of integral equations of elasticity', J. Eng. Mech., 114, 1028-1044 (1988).

6. A. Portela, M. H. Aliabadi and D. P. Rooke, 'The dual boundary element method: Effective implementation for crack problems', Int. J. Numer. Meth. Engng., 33, 1269-1287 (1992).

7. A. Portela, M. H. Aliabadi and D. P. Rooke, 'Dual boundary element incremental analysis of crack propagation', Comput. Struct., 46, 237-247 (1993).

8. A. Portela, Dual Boundary Element Analysis of Crack Growth, Computational Mechanics Publications, Southampton, 1993.

9. A. Portela and M. H. Aliabadi, Crack growth analysis using boundary elements (Software manual), Computational Mechanics Publications, Southampton, 1992.

10. L. J. Gray, L. F. Martha and A. R. Ingraffea, 'Hypersingular integrals in boundary element fracture analysis', Int. J. Numer. Meth. Engng., 29, 1135-1158 (1990).

11. T. Andersson, B. Fredriksson and B. G. A. Persson, 'The boundary element method applied to two dimensional contact problems', in Proc. 2nd Int. Seminar on Recent Advances Boundary Element Methods, CML Publications, Southampton, 1980, pp. 247-263.

12. T. Andersson and B. G. A. Persson, 'The boundary element method applied to two dimensional contact problems', in C. A. Brebbia (ed.), Progress in Boundary Elements, Vol. II, Pentech Press, London, 1982.

13. F. Paris and J. A. Garrido, 'An incremental procedure for friction contact problems with the boundary element method', Eng. Anal. Boundary Elements, 6, 202-213 (1989).

14. K. W. Man, M. H. Aliabadi and D. P. Rooke, 'BEM frictional contact analysis: Load incremental technique', Comput. Struct., 47, 893-905 (1993).

15. O. A. Olukoko, A. A. Becker and R. T. Fenner, 'A review of three alternative approaches to modelling frictional contact problems using the boundary element method', Proc. R. Soc. Lond. A, 444, 37-51 (1994).

16. G. Karami and R. T. Fenner, 'Analysis of mixed mode fracture and crack closure using the boundary integral equation method', Int. J. Fract., 30, 13-29 (1986).

17. A. P. S. Selvadurai and M. C. Au, 'Cracks with frictional surfaces: A boundary element approach', in Proc. 9th Boundary Elements Conference, Springer, Berlin, 1988, pp. 211-230.

18. A. P. S. Selvadurai and M. C. Au, 'Crack behaviour associated with contact problems with non-linear interface constraints', in BETECH '89, Proc. Boundary Element Technology Conf., Computational Mechanics Publications, Southampton, 1989, pp. 3-17.

19. C. Scavia, 'A numerical technique for the analysis of cracks subjected to normal compressive stresses', Int. J. Numer. Meth. Engng., 33, 929-942 (1992).

20. J. Tuhkuri, 'Experimental investigations and computational fracture mechanics modelling of brittle ice fragmentation', Dr. Tech. Thesis, Helsinki University of Technology, Acta Polytechnica Scandinavica, Me 120, Helsinki, 1996.

21. F. J. Rizzo, 'An integral equation approach to boundary value problems of classical elastostatics', Quarter. Appl. Math., XXV, 83-95 (1967).

22. T. A. Cruse, 'Numerical solutions in three dimensional elastostatics', Int. J. Solids Struct., 5, 1259-1274 (1969).

23. J. Tuhkuri, 'Boundary element analysis of cracks under normal compressive stresses', Espoo, Helsinki University of Technology, Ship Laboratory, Report M-197, 1995.

24. G. C. Sih and H. Liebowitz, 'Mathematical theories of brittle fracture', in H. Liebowitz (ed.), Fracture, Vol. II, Academic Press, New York, 1968, pp. 67-190.

25. J. R. Rice, 'A path independent integral and the approximate analysis of strain concentration by notches and cracks', J. Appl. Mech., 35, 379-386 (1968).

26. M. H. Aliabadi, 'Evaluation of mixed-mode stress intensity factors using the path independent J-integral', in Proc. Boundary Elements in Engineering XII. Computational Mechanics Publications, Southampton, 1990, pp. $281-291$.

27. A. C. Palmer and J. R. Rice, 'The growth of slip surfaces in the progressive failure of over-consolidated clay', Proc. $R$. Soc. Lond. A, 332, 527-548 (1973).

28. V. C. Li, 'Mechanics of shear ruptures applied to earthquake zones', in. B.K. Atkinson (ed.), Fracture Mechanics of Rock, Academic Press, London, 1987, pp. 351-428.

29. F. Erdogan and G. C. Sih, 'On the crack extension in plates under plane loading and transverse shear', J. Basic Eng., 85, 519-527 (1963).

30. G. C. Sih, 'Strain-energy-density factor applied to mixed mode crack problems', Int. J. Fract., 10, 305-321 (1974).

31. M. A. Hussain, S. L. Pu and J. Underwood, 'Strain energy release rate for a crack under combined mode I and mode II', in Fracture analysis, American Society for Testing and Materials, STP 560, 1974, pp. 2-28. 
32. A. R. Ingraffea, 'Theory of crack initiation and propagation in rock', in B. K. Atkinson (ed.), Fracture Mechanics of Rock. Academic Press, London, 1987, pp. 71-110.

33. R. V. Goldstein and R. L. Salganik, 'Brittle fracture of solids with arbitrary cracks', Int. J. Fract., 10, $507-523$ (1974).

34. S. Nemat-Nasser and H. Horii, 'Compression-induced nonplanar crack extension with application to splitting, exfoliation and rockburst', J. Geophys. Res., 87, B8, 6805-6821 (1982).

35. A. P. S. Selvadurai, 'Boundary element modelling of geomaterial interfaces', in A. P. S. Selvadurai and M. J. Boulon (eds.), Mechanics of Geomaterial Interfaces, Elsevier Science B.V., Amsterdam, 1995, pp. 173-197.

36. Y. C. Hsu, 'The infinite sheet with cracked cylindrical hole under inclined tension or in-plane shear', Int. J. Fract., 11, 571-581 (1975).

37. M. Comninou and F.-K. Chang, 'Effects of partial closure and friction on a radial crack emanating from a circular hole', Int. J. Fract., 28, 29-36 (1985).

38. M. F. Ashby and S. D. Hallam (née Cooksley), 'The failure of brittle solids containing small cracks under compressive stress states', Acta Metall. Mater., 34, 497-510 (1986).

39. S. D. Cooksley, 'Yield and fracture surfaces of brittle solids under multiaxial loading', Ph.D. Thesis, Department of Engineering, University of Cambridge, 1984.

\section{Additional reference for the Appendix}

40. I. S. Gradshteyn and I. M. Ryzhik, Table of Integrals, Series, and Products, Academic Press, New York, 1980. 